\title{
Temperar a alma, retemperar os músculos: corpo e História da Educação em Afranio Peixoto
}

José G. Gondra

Resumo: Neste estudo, abordamos alguns aspectos do livro Noções de História da Educação, de Afranio Peixoto. No que se refere aos princípios que inspiram, ordenam e calibram a escrita, observa-se que se trata de campanha em favor da educação integral, na qual os aspectos físico, moral e intelectual deveriam estar articulados e equilibrados. Nem ausência, nem excesso, pois o princípio geral é o da moderação. Observamos, igualmente, que o curso "ditado" no Instituto de Educação é convertido em textbook; uma espécie de dicionário da pedagogia, que procura oferecer às futuras professoras um repertório no qual o tempero dos músculos e da alma roteirizam a história. Por fim, marcada pelo presente do autor, a narrativa de Peixoto procura organizar o presente das professoras, como forma de conduzir suas condutas e definir quando, como e aonde chegar com a intervenção calculada, científica e permanente sobre seus corpos e os corpos dos outros.

Palavras chave: educação; história; corpo.

\section{Seasoning the soul, refreshing the muscles: body and History of Education in Afranio Peixoto}

Abstract: In this study, we discuss some aspects of Afranio Peixoto's book: Noçoes de História da Educação. With regard to the principles that inspire, order and calibrate writing, it appears that they consist in a campaign in favor of Comprehensive Education in which the physical, moral and intellectual aspects should be articulated and balanced. Neither absence nor excesses, because the general principle is moderation. We also noted that the course "dictated" at the Instituto de Educação is converted into a textbook; a kind of dictionary of pedagogy aiming to offer future teachers a repertoire in which the spice of the muscles and soul serve as the script of the story. Finally, marked by this author's present, Peixoto's narrative seeks to organise the teachers' present in order to guide their attitudes and define when, how and where to get with the calculated, scientific and permanent intervention about their bodies and the bodies of others.

Key words: education; body; history.

Professor adjunto na Universidade do Estado do Rio de Janeiro (UERJ), Brasil. gondra.uerj@ gmail.com

Pro-Posiçôes, Campinas, v. 22, n. 3 (66), p. 19-34, set./dez. 2011 
Obra para toda a vida. Desse modo, Afrânio Peixoto descreve a tarefa educativa na terceira edição de Noçães de História da Educação (1942). Obra que, por sua vez, se apresentava com a finalidade expressa de "fazer homens de bem". Fazer que mereceu tratamento histórico no referido livro, mas que a ele não se restringiu, pois a problemática da formação humana comparece de diferentes modos na extensa produção escrita de Peixoto, como no A educação da mulher e nos seus compêndios de higiene, por exemplo. Cabe assinalar que, para o autor, a fabricação dos homens de bem deveria seguir um conjunto de princípios articulados na História da Educação que narra. Princípios que inspiram e calibram a narrativa, orientados pelos compromissos programáticos do autor, por sua condição de médico, pela reforma com a qual se encontra alinhado, pela participação no Conselho Diretor da Associação Brasileira de Educação, por sua filiação ao Instituto Histórico e Geográfico do Brasil (IHGB), pelo exercício do magistério de Higiene e Medicina Legal da Universidade do Brasil e por suas relaçóes no campo literário e na própria Academia Brasileira de Letras.

Múltiplo pertencimento, que ajuda a compreender os debates nos quais se envolve e o tom que imprime a eles. No caso da História da Educação, o livro se constitui em testemunho do curso de História da Educação por ele ministrado no Instituto de Educação, em 1932. O curso-livro termina por formular uma espécie de grade de inteligibilidade para a História da Educação, ao mesmo tempo que apresenta e defende princípios doutrinários que deveriam ordenar a educação da casa e da escola. O curso, cumpre assinalar, é transformado em livro na esfera de outra estratégia dos que se autointitularam renovadores, a editorial.

Para fazer as reformas chegarem a bom termo, os líderes desse movimento reformador agiram em várias pontas. No associativismo docente, criaram e animaram a Associação Brasileira de Educação; no plano do executivo, realizaram reformas educativas em várias capitais do Brasil; no campo da formação, não cessaram de interferir na formação dos professores, seja na dos que se encontravam em serviço, seja na dos que realizavam a formação prévia. Para os dois casos, a ação editorial foi uma estratégia necessária.

No que se refere aos princípios que inspiram, ordenam e calibram a escrita de Peixoto, neste estudo, destaco um deles. Trata-se de sua adesão e campanha por uma educação integral, na qual os aspectos físico, moral e intelectual deveriam estar presentes, articulados e equilibrados. Nem ausência, nem excesso. O princípio geral é o da moderação que, na linearidade que propõe e com os exemplos edificantes que localiza, põe o leitor em contato com culturas ancestrais, para delas recolher as liçôes e os contraexemplos que lhes parece interessar. Com esse jogo, procura estabelecer uma espécie de encontro de presentes; régua e compasso para que as futuras professoras pudessem aquilatar o programa delineado e aderir às apostas formuladas ao longo da narrativa. Portanto, o tratamento dispensado ao corpo

Pro-Posições, Campinas, v. 22, n. 3 (66), p. 19-34, set./dez. 2011 
deve ser compreendido no interior do projeto da educação integral, funcionando como medida para destacar os limites e a potência da educação dos guerreiros, a febre da erudição, a cavalaria, as cruzadas, os suplícios, os saberes e outras atividades proporcionais às idades da vida e às condiçōes dos discípulos. Nesse caso, surdos-mudos, cegos, deficientes mentais e menores abandonados comparecem como "especiais", um duplo da educação dos "normais" que o médico privilegia ao longo da história que escreve para professoras.

Nesta investigação, procurei explorar uma indagação complementar. No jogo instituído pelo "mestre de mestres", que outros elementos ele emprega para legitimar o programa e os princípios contidos em sua narrativa? Crítico da erudição estéril, adepto de uma educação progressiva e ativa, não hesita em recorrer à aparelhagem científica disponível, construindo um texto folheado, no qual proliferam citações, muitas delas em latim, francês e inglês; remissōes; notas; sínteses; prefácio; e índices - das matérias e dos autores citados (331, na segunda edição). O caráter ilustrado do livro, uma diferença creditável ao método pedagógico defendido, parece, contudo, ser insuficiente para retirar do livro seu caráter enciclopédico ${ }^{1}$. Aliás, o emprego desse recurso parece reforçar esse traço. Cabe, assim, indagar a respeito dos princípios que modulam a enciclopédia que o médico baiano oferece como base para a formação de professoras primárias.

\section{Noções de História da Educação}

Evolutivo e linear se constituem em adjetivos facilmente empregados para definir o tipo de história praticada por Afranio Peixoto. Não fosse o enquadramento geral perceptível no sumário do livro-curso, ele se veria assumido e reforçado por meio de dois dispositivos textuais.

A cronologia que precede cada capítulo antecede e sintetiza a matéria a ser tratada, mas já aí mesmo trabalhada. Um único exemplo, para demonstrar esse efeito. Ao ingressar de modo mais detalhado no exame da História da Educação dos EUA, apresenta uma súmula com 82 pontos $^{2}$, por meio dos quais o leitor é conduzido por uma linha do tempo que recobre nove séculos (1001-1933), na qual sucedem acontecimentos de ordens variadas, com ênfase naqueles que, segundo o autor, aconteceram pela primeira vez, como a chegada do islandês à América do

I. O livro possui um total de 99 ilustrações, sendo 88 desenhos e II fotografias. No capítulo relativo à Escola Nova, chama atenção a fotografia coletiva, a única que ocupa página inteira, na qual aparecem "os pioneiros da escola nova", como consta na descrição da mesma, que são: Ovide Décroly, Pierre Bovet, B. Ensor, Edouard Claparède, Paul Geheeb e Adolphe Ferrière (1942, p. 334).

2. Cf. p. 24I-244 da terceira edição, de 1942, selecionada para efeitos de remissão neste artigo. Nas edições anteriores a paginação não é a mesma, tendo em vista os projetos editoriais de 1933 e 1936, assim como as atualizações feitas no livro em análise. 
Norte, em 1001; a fundação da primeira colônia (1607); a primeira escola da "Nova Amsterdam" (1638); a primeira escola pública feminina no Mississipi (1801); o primeiro tratado sobre a educação (1808); a primeira escola normal oficial (1839); o primeiro jardim de infância (1860), finalizando com a proibição antialcoólica reduzida (1933), por exemplo3.

O segundo dispositivo pode ser localizado, por exemplo, na página 235. Nesse caso, antes de encerrar a parte em que abordava as contribuiçóes de Auguste Comte, John Stuart-Mill, Herbert Spencer, Alexandre Bain, Sigmund Freud e o ensino dos anormais 4 , assinala que "cronologicamente" dever-se-ia tratar da escola nova, da escola ativa, da escola progressiva que, segundo ele, "vem do fim do século XIX, e vai por diante, agora, e para o futuro". Contudo, alerta que não convinha fracionar o estudo, remetendo o leitor para o capítulo no qual vai tratar especificamente do tema da escola nova, o último capítulo do livro. Com isso, vai consolidando sua fidelidade à cronologia como princípio ordenador da narrativa.

Mas o que esperar de um "curso ditado" em 1932, publicado pela primeira vez em 1933, reeditado e atualizado em 1936 e 1942? A narrativa empregada por Peixoto era a possível para seu tempo e, nesse sentido, ela se constitui em um bom exemplar. Ao lado de um amarramento cronológico muito definido e reforçado ao longo de todo o texto, a história narrada pelo médico baiano também cumpre a função de compendiar às futuras professoras primárias ${ }^{5}$ aquilo que julga ser o

3. O capítulo relativo à América Latina também se constitui em um bom exemplo da adesão à cronologia como ordenador capital da história. A experiência da América Latina é condensada em 126 pontos, recobrindo do ano 1000 a. C. (quando os Maias se mudaram das terras baixas e úmidas de lucatan, no México) até 1935 ("Rebelião no Brasil". "Morre o general Juan Vicente Gomez, tirano da Venezuela, por 25 anos". "Abolição da emenda Platt, em Cuba"). Com esses I 26 destaques, chama atenção para conquistas, batalhas, rebeliões, ditaduras, processos de independência, revoluções, criação da imprensa, terremotos e pouco destaque dá à malha escolar, salvo para a criação das universidades. Neste caso, chama atenção a inversão operada, pois o condensado inicial é maior que a parte na qual reflete sobre a problemática da educação na América Latina. Esta se encontrava abandonada. Sobre ela apresenta os expressivos números do analfabetismo. Tudo isso porque "A história da América Latina é uma ladainha de caudilhos, tiranos, bandidos, em que os Rosas, Francia, Melgarejo, Porfirio Dias se sucedem, trágicos e ridículos, sanguinários e vorazes, às vezes místicos" (1942, p. 270). Na edição anterior, o diagnóstico continha outros elementos, como se pode observar: "Panamá, Bolívia, Paraguai... não diferem da Argentina, Chile, Peru, México, todos parecidos conosco, Brasil. Frutos da falta de educação. Sobretudo educação popular. Há universidades, há faculdades de direito, medicina, engenharia... [...] Não importa, a má educação é tanto das classes dirigentes como da massa popular. [...] A história da América Latina é uma ladainha de caudilhos, tiranos, bandidos, em que os Rosas, Francia, Porfirio Dias se sucedem, trágicos e ridículos, sanguinários e vorazes, às vezes místicos." (1936a, p. 219).

4. Surdos-mudos, cegos, deficientes mentais e menores abandonados. Considera os menores abandonados como "não normais", do ponto de vista social (1942, p. 238).

5. A questão de gênero não é gratuita, pois ela corresponde à posição defendida por Afrânio Peixoto ao longo de todo o livro. Nesse caso, ao descrever seu livro como "recordação para

Pro-Posições, Campinas, v. 22, n. 3 (66), p. 19-34, set./dez. 2011 
patrimônio necessário para o exercício da docência. Trata-se de lhes permitir perceber as tradições, as heranças, os precursores e os princípios doutrinários gerais que modulavam as açóes educativas de modo que elas pudessem aquilatar, dimensionar a tradição a que deveriam pertencer, com base no legado que o mestre lhes oferecia. Nessa linha, o livro funciona como uma espécie de repertório alargado das experiências educativas vividas pela humanidade. O que deveria ser extrato parece funcionar como enciclopédia, cujos traços se evidenciam na espessura do tempo com a qual trabalha — os nove séculos — , mas também pelos procedimentos mais internos do texto. Nesse sentido, o emprego de uma aparelhagem científica na qual sobressai o jogo duplo da remissão a textos/autores e a imagens, em sua grande maioria desenhos dos autores referidos, parece robustecer o caráter enciclopédico do que se pretendia que fosse um text-book. Fortalecimento que também decorre da erudição verificável nas remissões e nas citações em latim, francês e inglês presentes ao longo das "Noções" redigidas por Peixoto. Não bastassem esses elementos para tornar perceptível a enciclopédia peixotiana, os alinhamentos que elabora no início e/ou ao fim de cada tema e/ou autor abordado impóem ao leitor um roteiro de leituras e um modo de articulá-las que supõe um domínio refinado das mesmas.

Evolutivo, linear e enciclopédico! Esta seria uma forma de tipificação do livro de História da Educação escrito por Peixoto. Contudo, ao se manter neste registro, que novos aportes ele proporciona? De meu ponto de vista, pouca coisa. Seria apenas uma espécie de recorrência que, para uns, poderia soar como uma espécie de denúncia de um tipo de história que não se deve fazer. Pretendo tomar distância desta posição pelos riscos que ela representa para pensar o livro nas condições que o possibilitaram e na diferença que pretende instaurar, e esta aqui talvez seja a principal contribuição deste artigo.

O livro foi antes um curso. Curso que, por sua vez, se encontrava desenhado por uma instituição; no caso, o Instituto de Educação do Rio de Janeiro. Mas um curso em programa de formação de professoras primárias na esfera da reforma conduzida por Anísio Teixeira ${ }^{6}$, conterrâneo de Afrânio Peixoto e com quem este partilhou algumas iniciativas importantes, no âmbito do Instituto, na reitoria da Universidade do Distrito Federal ${ }^{7}$ e na Associação Brasileira de Educação ${ }^{8}$, por exemplo. Com isso, o curso acompanha o programa da disciplina, introduzindo novos elementos. Programa, portanto, ajustado, como se pode observar em rela-

professoras", antecipa claramente a exclusividade do magistério feminino para o magistério primário. Defesa que é retomada em outras produções do autor, como no livro A educação da mulher (1936b).

6. Diretor Geral da Instrução Pública (1931-1935). Sobre Anísio, cf. estudo de Nunes (2000) e também a Biblioteca Virtual Anisio Teixeira (http://www.bvanisioteixeira.ufba.br/). Acesso em 28 de julho de 2009.

7. Cf. estudo de Mendonça, 2002.

8. Cf. o estudo de Carvalho, 1998.

Pro-Posiçôes, Campinas, v. 22, n. 3 (66), p. 19-34, set./dez. 2011 
tório que Peixoto assina no periódico Arquivos do Instituto de Educação, em 1935. Nesse relato, apresenta o programa de 20 pontos, iniciando com a educação dos selvagens e primitivos, finalizando com a Escola Nova'.

Como se pode ver no Quadro I, o livro segue a mesma estrutura do programa da disciplina, com a diferença de estar repartido em três grandes temporalidades.

Quadro I- Estrutura de Noções de História da Educação

\begin{tabular}{|l|l|l|}
\hline Educação Antiga & $\begin{array}{l}\text { Educação Medieval e } \\
\text { Moderna }\end{array}$ & Educação Contemporânea \\
\hline Introdução & Patrística, Monástica & $\begin{array}{l}\text { Pestalozzi, Gerard, Froebel, } \\
\text { Herbart, J. P. Richter. Ensino } \\
\text { Mútuo }\end{array}$ \\
\hline Educação Arcaica & Invasão Árabe & $\begin{array}{l}\text { Comte, Stuart Mill, Spencer, } \\
\text { Bain, Freud. Ensino de } \\
\text { anormais }\end{array}$ \\
\hline Grécia & Escolástica & Estados Unidos \\
\hline Roma & Renascimento & América Latina \\
\hline & Idade Moderna & Brasil \\
\hline & Locke, Rousseau & Escola Nova \\
\hline
\end{tabular}

Com relação aos compêndios de História da Educação que haviam inspirado Peixoto, sobressaem-se dois norte-americanos, como registra no último item do relatório da disciplina de $1935^{10}$.

9. Um contraste mais minucioso com a experiência do ensino de história da educação que antecede e sucede o curso de Afrânio ainda está por ser feita. Para o que antecede, uma leitura do Programa da disciplina de 1929 fornece pistas importantes. Para o que acontece depois, uma leitura do livro de Theobaldo Miranda Santos, substituto do livro de Peixoto na Coleção Atualidades Pedagógicas, se constitui em um exercício necessário. A esse respeito, recomendo a leitura do trabalho de Vieira (20 I I). Para compreender mais precisamente a narrativa de Peixoto, ao lado desses dois movimentos, cumpre observar o jogo de rebatimentos aos livros de História da Educação. Nesse caso, um contraste com os livros de Paul Monroe e Stephen Duggan se faz necessário, dado os créditos atribuídos aos dois pelo próprio autor. Nesse sentido, conferir Gondra e Silva (20 I lb) e Gondra e Sily (20 I I). Já para observar a prática historiadora de Peixoto, recomendo o texto de Gondra e Silva (20 | la). Para outras observações a respeito deste autor, ver os estudos de Ribeiro (1950), Lopes (2002) e Rocha (2002), por exemplo.

10. Note-se que Peixoto apoia sua iniciativa na experiência norte-americana, definindo procedimentos a serem empregados no ensino de História da Educação. No início deste mesmo relatório, ele oferece outros elementos que ajudam a pensar a execução do programa. Para ele, o processo de ensino de História da Educação só poderia ser o informativo e o processo de debate ou seminário, pois que não comporta a experimentação. Em seguida, dá dois testemunhos pessoais: do curso de 1933 e do curso de 1934. Em 33, os alunos escolheram um educador ou um

Pro-Posições, Campinas, v. 22, n. 3 (66), p. 19-34, set./dez. 2011 


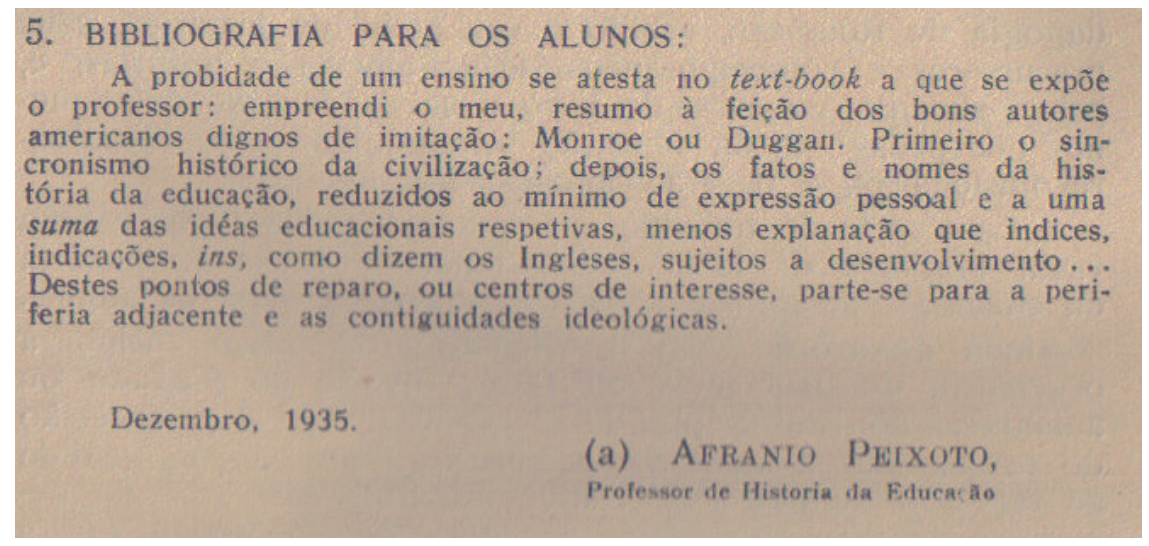

No resumo do brasileiro, há quatro elementos para os quais se volta e, salvo os dois últimos, os outros se constituem em uma particularidade da sua narrativa: A educação arcaica, América Latina, Brasil e Escola Nova ${ }^{11}$. Tais elementos, ainda que nucleados em um capítulo, participam e estruturam a narrativa de Peixoto posto que, no limite, o programa reformador do qual participa é introduzido em vários momentos do texto como um modelo adotado como critério para avaliar as diversas experiências da história da civilização que examina. Do programa reformador, da escola ativa, progressiva e da pedagogia científica por ele defendida, para efeitos deste artigo, vou me deter em um ponto: o modo como se refere ao corpo como problema a ser enfrentado pela nova pedagogia.

\section{Corpo equilibrado, sujeitos normalizados}

A História da Educação se constitui, para AP, em uma oportunidade de demonstrar as falências de uma "velha" forma de educação. As evidências do esgotamento da "velha pedagogia" não cessam de ganhar visibilidade na narrativa do professor-autor de História da Educação, ao se referir a métodos de ensino, saberes

sistema de educação. Já em 34, os assuntos foram sorteados para evitar que "a simpatia levasse muitas delas ao mesmo tema". Ao lado desse trabalho, as alunas leram Emílio, de J. J. Rousseau. De acordo com o relato, o livro foi discutido, a pedagogia de Rousseau foi criticada, sabido seu ambiente histórico, seus precursores e seus contemporâneos, ideias alheias e próprias e, principalmente, seu êxito e sua condenação. Para Peixoto, a censura ao livro implica menos um julgamento da pedagogia e da educação do que uma rejeição às propostas dos filósofos considerados revolucionários e dos tradicionalistas reacionários.

I।. As transformações que instaura com a introdução de reflexões a respeito da educação no oriente, no Oriente Médio, Estados Unidos e América Latina encontram-se associadas à posição de que História da Educação é história da civilização e sua adesão ao pan-americanismo. Já tive oportunidade de explorar esses aspectos mais detidamente em outro texto. A esse respeito, cf. Gondra; Ascolani, 2009. 
escolares, formação de professores, cultura literária, relação com as famílias, espaços e tempos escolares, financiamento e à questão da educação do corpo. Observar o campo de presença produzido por Peixoto em relação a esse ponto supõe analisar as visibilidades a que o corpo é submetido. No caso em questão, há, no mínimo, quatro rebatimentos que podem ser percebidos ao longo da narrativa em exame. Rebatimentos que devem ser percebidos como vértices de um quadrilátero, sem que se possa isolar um dos outros, e para os quais quero chamar atenção.

A presença do corpo na narrativa peixotiana se faz por meio do projeto de educação integral, no qual o sujeito se vê descrito com base no triângulo moral, físico, intelectual. A boa formação humana supõe observar os três lados, mas também o estabelecimento de um equilíbrio entre eles. Portanto, não se trata de triangular esses três termos de qualquer forma. A figura deve ser equilátera, de modo a assegurar a produção de "homens de bem".

O modelo de homem triangulado, homem equilibrado que vai sendo introduzido na narrativa desde seu início, no jogo dos exemplos e contraexemplos que AP oferece às suas leitoras. Uma referência inicial pode ser localizada quando aborda a educação grega e cita Platão, para quem a educação teria por fim "dar ao corpo e à alma toda a beleza e toda a perfeição de que são suscetíveis" (Peixoto, 1942, p. 45).

A experiência grega funciona como condição para que Peixoto dê visibilidade ao modelo de educação integral. Ao se referir à cultura ateniense, destaca a importância da prática de jogos, cantos, poesias e fábulas no ambiente doméstico até os sete anos. $\mathrm{Na}$ escola, a partir dessa idade, novas rotinas. Muda-se a vestimenta e se investe na ginástica, jogos, gramática, leitura, lógica e na música — programa a ser desenvolvido de modo proporcional às idades e aos estratos educativos. Para Peixoto, a experiência ateniense constitui-se em expressão da fórmula moderna da educação pela instrução, que se resume em três palavras, três ideias, três sistemas:

- Eucosmia - a graça das maneiras

- Sofrosine- o governo de si mesmo; o self-control

- Aretê - a perfeição do corpo e da alma

Com tais destaques, vai construindo o argumento em favor da intervenção sobre os comportamentos, os corpos e as almas, com vista a proporcionar a internalização das regras, o autogoverno. O refinamento desse programa parece encontrar expressão mais acabada em Herbert Spencer (1820-1903), o qual reconhece o mérito de fazer crítica cerrada à educação tradicional ${ }^{12}$, de um excessivo intelectualismo e uma exigente formação moral e religiosa, em "desproveito da educação física, primordial e indispensável” (1942, p. 231). O jogo de reconhecimento e de aproximação das posiçōes de Afrânio com as do filósofo inglês se vê reforçado nas

12. "E ainda vigente", atualiza o autor (1942, p. 50.).

Pro-Posições, Campinas, v. 22, n. 3 (66), p. 19-34, set./dez. 2011 
filiaçôes que estabelece entre Spencer, Rousseau, Pestalozzi, Jeremy Benthan, Stuart Mill, etc.; e de todos eles com a Escola Nova. Nesse caso, chama atenção o fato de iniciar a cronologia do capítulo a respeito da Escola Nova com Spencer, ainda que ele não apareça na lista dos seus precursores, e que principia com remissão a uma iniciativa russa, protagonizada por Tolstoi, a partir de 1858. O motor da presença de Spencer na abertura desse capítulo parece objetivar o fortalecimento da tese da educação integral com a visibilidade que se dá ao livro Da educação intelectual, moral e fisica, do autor inglês ${ }^{13}$.

Outro rebatimento da problemática do corpo comparece no combate desenvolvido por Peixoto aos castigos físicos. Aqui, Peixoto fornece mais evidências de seu compromisso com matrizes médicas, jurídicas e religiosas, que paulatinamente se afastaram da tese do suplício como medida e condição para formar "homens de bem". Aproxima-se e adere de modo muito claro à tese da suavização das penas.

No que se refere aos castigos físicos, ao comentar a educação judaica, assinala que ela operava com a tese da maldade da natureza humana, cuja superação dependia da vara e da reprimenda, chamando atenção para a doutrina do Talmude $e^{14}$, livro sagrado dos judeus. Tal corpo doutrinário ainda que essa cultura convivesse com outras tradiçôes ${ }^{15}$, prescrevia que a criança deveria ser punida com uma mão e acariciada com ambas, como Peixoto destaca, recorrendo a dois provérbios do universo israelense:

- A loucura está no coração da criança, mas a vara do castigo o expelirá dele.

- O menino abandonado a si mesmo será a vergonha de sua mãe; a vara e a reprimenda dão a sabedoria $(1942$, p. 35)

O tema do castigo reaparece no momento em que Peixoto trata da disciplina na educação romana, afirmando que açoites e provaçōes eram aplicados ao discipulus: "A férula, de ferire, tanto é a vara, o açoite, chicote ou chibata, como é a palmatória, com que se batia na palma das mãos. Este suplício romano teve largo uso universal, quase até nossos dias e, não duvido, haja alguém por aí além, ainda tal escola, em que se use..." (Ibidem, p. 62)

Antes, contudo, ao se referir à educação na Índia, registra a presença dessa prática, chamando atenção para o emprego regular de varas, mas, sobretudo, para um que considera original: a aspersão e a imersão dos corpos na água fria que, ironiza $^{16}$, "deviam ser amáveis ao clima indiano".

13. Para uma reflexão mais detida deste ponto, cf. Gondra, 2004.

14. Tahnud, no original, traduzido como "instrução" (1942, p. 35).

15. Procedimento assemelhado vai adotar em outros momentos em que trata dessa questão e de outros temas, como se pode observar no caso dos gregos (1942, p. 45).

16. A ironia consiste em uma figura de linguagem que procura assinalar o contrário daquilo que se pensa, deixando entender uma distância intencional entre aquilo que dizemos e aquilo que realmente pensamos. Na literatura, a ironia é a arte de gozar com alguém ou de alguma coisa,

Pro-Posiçôes, Campinas, v. 22, n. 3 (66), p. 19-34, set./dez. 2011 
É, pois, contra a longa permanência dos corpos castigados que o livro também é redigido, com sucessivos retornos a essa questão, para reforçar a necessidade de abandono de tal prática em favor de mecanismos que permitissem uma interiorização do poder mais humanizado e mais eficaz. Nesse caso, a ação sobre os aspectos morais, os bons exemplos, uma formação científica das professoras, pautada por métodos e saberes igualmente científicos, delineiam os novos termos que deveriam orientar a ação sobre as resistências dos alunos às atividades escolares.

Outro rebatimento da questão corporal se refere à questão dos sexos. A "velha pedagogia" aparece associada a um modelo educativo segundo o qual meninos e meninas estudavam separadamente. Tomando distância dessa tradição, Peixoto abraça a causa da coeducação para demonstrar os benefícios morais, pedagógicos e financeiros de tal medida. Para ele, a civilização em marcha não podia renunciar a uma educação comum para meninos e meninas. Tratava-se de produzir uma nova relação com os corpos infantis, a qual, na perspectiva do autor, seria mais útil para a sociedade como um todo.

A primeira manifestação a respeito desse ponto pode ser encontrada quando ele trata da educação arcaica. Ao se debruçar sobre a experiência hindu, uma sociedade de castas, observa que a educação era reservada às castas superiores, sendo impedida aos párias, aos indignos e aos infames. Nessa sociedade, a mulher indiana possuía estatuto equivalente ao de escravos e párias, pois se partia do preceito de que "a mulher letrada não obedece, nem quer trabalhar". Para marcar a atualidade desse tipo de percepção, recorre ao provérbio ocidental: "desconfie da mula que faz him e da mulher que sabe latim..." (Ibidem, p. 22). Insinua, desse modo, sua percepção acerca do funcionamento da sociedade e da participação feminina.

O tema é retomado inúmeras outras vezes ao longo do texto, de modo a reapresentar regularmente o problema da educação feminina às alunas-leitoras. Quando remete aos tratados escritos por Xenofonte (430-354), assinala que a educação da mulher foi abordada no ${ }^{17 " E c o n o ̂ m i c o ", ~ q u e ~ d e f e n d e ~ q u e ~ a ~ e d u c a c ̧ a ̃ o ~ f e m i n i n a ~ d e-~}$

com vista a obter uma reação do leitor, do ouvinte ou do interlocutor. Ela pode ser utilizada, entre outras formas, com o objetivo de denunciar, de criticar ou de censurar algo. Para tal, o locutor descreve a realidade com termos aparentemente valorizantes, mas com a finalidade de desvalorizar. A ironia convida o leitor ou o ouvinte a ser ativo durante a leitura, para refletir sobre o tema e escolher uma determinada posição. A ironia se constitui em recurso estilístico empregado regularmente por Afrânio Peixoto, quando quer demonstrar seu espanto ou desacordo profundo com um determinado tema, como se pode ver neste caso.

17. Discípulo de Sócrates, Xenofonte trata, no Econômico, em primeiro lugar, da administração do oikos. De acordo com Barros (201 I, p. 2), oikos abarca a habitação propriamente dita, a casa (residência), e os bens do senhor do oikos, estejam dentro ou fora da polis (Econômico, I, 5). Oikonomía consiste na sábia administração dos oikos, sendo indiferente que essa administração se refira ao oikos de outrem e se faça mediante salário (Econômico, I, I e 4). "Sábia administração" compreende a conservação, a ampliação e a prosperidade do oikos, o que exige uma gestão patrimonial com lucro. Introduz-se aqui a ideia de bem, riqueza (krémata), que, por sua vez, nos

Pro-Posições, Campinas, v. 22, n. 3 (66), p. 19-34, set./dez. 2011 
veria ficar "comprimida ao lar, sem curiosidades naturais, com virtudes domésticas recebidas da mãe e que o marido continua a educar, para o lar: dispenseira, esposa, mãe ... e basta. Enfim, foi alguma coisa pensar nas mulheres...” (1942, p. 59)

No entanto, esse tema, combinado com os demais, vai merecer um tratamento diferenciado. No mesmo ano em que se publica a segunda edição do Noçôes, também é publicado o livro $A$ educação da mulher que se encontra estruturado em duas partes: "O que foi" e "O que deve ser". Na primeira parte, o autor trabalha com periodização semelhante à empregada no Noçôes, remetendo a um conjunto de experiências bem diversificadas, das quais extrai exemplos de ação feminina em prol da educação e dos benefícios daí decorrentes. Na segunda parte, oferece argumentos extraídos da anatomia, da fisiologia e da psicologia, para sustentar a necessidade da educação feminina, mas também uma orientação científica para essa educação. Tudo isso aparece antecipado no prefácio, no qual Peixoto afirma que não se tratava de um livro didático sobre a educação da mulher, sendo "antes, sobre o assunto, ensaio, às vezes polêmico, de propaganda e justificativa dessa educação". Educação feminina que deveria ser pautada pela coeducação, orientada pelo trabalho, sem descurar da educação física, descrita como mais necessária às mulheres do que aos homens.

Por fim, o último vértice do quadrilátero reenvia à questão do corpo docente. Para Peixoto, a primeira educação escolar deveria se constituir em um trabalho exclusivamente feminino. Para ele, a mulher reunia melhores condições físicas, morais e intelectuais para educar a criança na fase inicial da escolarização, devendo o homem ser liberado para outras atividades no mundo do trabalho. Como se pode perceber, o autor defende que esse estrato da corporação fosse ocupado exclusivamente pelas mulheres.

Tal posição vem apoiada nos exemplos que seleciona ao longo do curso-livro, que parece adquirir força de exemplaridade, quando se refere à experiência norte-americana. Tomando Horace Mann como o criador da escola pública na América, atribui a ele também a defesa da coeducação e da natureza feminina para o magistério primário. Ao lado do caráter vocacional para o magistério primário atribuído às mulheres, Peixoto apresenta dois elementos complementares que merecem ser observados: ele também se refere ao caráter econômico desse trabalho, que, para os homens, seria uma "capitulação", mas para as mulheres, ainda nesse estado econômico, constituiria uma seleção que as engrandeceria, pois adquiririam digna autonomia do trabalho. O outro é o quadro da Guerra de Secessão, de 1851 a 1855 . Homens chamados às fileiras foram então substituídos por mulheres que deram prova de sua capacidade. E conclui: "veio daí que nos Estados Unidos,

remete à questão da adequação dos meios aos fins na administração dos recursos (Cf. www. paideuma.net/gilda4.doc. Acesso em: 20 ago. 201 I). 
ao contrário da Europa, a instrução primária é quase um privilégio feminino". (1942, p. 249)

Observar as visibilidades a respeito do corpo operadas na narrativa em questão nos permite pensar a força do presente e o grau de envolvimento de Peixoto com o programa reformador em curso. Nesse sentido, o livro é marcado por uma pragmática que pode ser evidenciada em várias pontas. Para efeitos desta reflexão, coube chamar atenção para o modo como o autor seleciona determinadas questôes para funcionar como núcleo da argumentação e de condução da narrativa. No caso do corpo, as visibilidades conferidas à mulher, à coeducação, aos corpos educados e aos corpos integralizados confirmam o caráter pragmático do curso-livro e a função que este pretendeu cumprir junto às jovens e futuras professoras primárias.

\section{Considerações finais}

Como assinalado no discurso introdutório, logo no segundo parágrafo, apoiado em Bergson ${ }^{18}$, o presente se constitui na ponta extrema do passado. Ponta extrema que demandava ser alterada. Percepção que reforçava ainda mais a necessidade de interferir no curso das coisas, pela via da escola. Assim, o ciclo parece se fechar. O mundo da desordem que observa na América Latina, da qual o Brasil faz parte, como faz questão de assinalar, precisava ser disciplinado, regulado, governado. $\mathrm{Na}$ ótica do médico baiano, do erudito homem de letras e da política, a reforma da sociedade exigia a reforma das escolas, que se deveria iniciar mais cedo, ser mais científica e durar mais tempo. Interferindo na ponta extrema do passado, sonhava e queria fazer os futuros professores sonharem com uma ordem educada, a ser obtida com o auxílio de uma escola renovada. A "recordação para professoras", como imaginara em seu curso e seu livro, também pode ser compreendida como uma espécie de propaganda das reformas que embalara e animara uma geração de homens e mulheres. Projeto esse forjado na luta por uma sociedade mais educada, mais disciplinada.

Reinscrito na ponta extrema daquele passado, naquele presente, o livro de História da Educação de Afranio Peixoto parece adquirir outra força, outro vigor, posto que a obra se afasta e já não é mais uma simples enumeração de datas, fatos, batalhas e heróis. Do mesmo modo, ainda não é uma história jurídica da educação. No front e no calor da batalha por uma pedagogia científica, por uma escola renovada, a narrativa do dr. Afranio parece ter sido modulada pelo (e ajustada ao) movimento renovador em curso no Brasil e no exterior. Programa (ou remédio) que deveria ser aplicado em vários países, mas, sobretudo, no Brasil e nos "tristes" e "atrasados" vizinhos da América Latina.

18. Para Bergson, o presente é apenas a ponta extrema do passado, e o futuro, o que o homem espera ou teme (1942, p. 10).

Pro-Posições, Campinas, v. 22, n. 3 (66), p. 19-34, set./dez. 2011 
Como é possível observar, o curso "ditado" no Instituto de Educação, no âmbito de uma reforma que o justifica e que procura legitimar, é transformado em um text-book; uma espécie de grande dicionário de pedagogia, oferecendo às futuras professoras um repertório e um vocabulário nos quais o tempero dos músculos e da alma roteirizam em parte a história que se escreve. Marcada pelo presente do narrador, a História da Educação e do corpo presente na narrativa de Peixoto, recuada a "uma ponta extrema", tem por finalidade organizar o próprio presente das professoras, como forma de conduzir suas condutas e definir quando, como e aonde chegar com a intervenção calculada, científica e permanente destas sobre suas vidas e sobre a vida dos outros.

\section{Referências bibliográficas}

BARROS, Gilda. O Econômico de Xenofonte - retrato da esposa ideal. Disponível em: <www.paideuma.net/gilda4.doc>. Acesso em: 20 ago. 2011.

CARVALHO, M. Molde nacional e forma civica - higiene, moral e trabalho na ABE. Bragança Paulista: EDUSF, 1998.

DUGANN, Stephen Pierce H. A student textbook in the History of Education. New York/ Chicago: D. Appleton and Company, 1916.

GONDRA, J. Artes de civilizar - medicina, higiene e educação escolar na Corte Imperial. Rio de Janeiro: EDUERJ, 2004.

GONDRA, J.; ASCOLANI, A. Pela classe, pelo livro: a fundação de uma História da Educação para professores, no Brasil e na Argentina. In: VIDAL, D.; ASCOLANI, A. (Org.). Reformas educativas no Brasil e Argentina. São Paulo: Cortez, 2009.

GONDRA, J.; SILVA, J. C. S. Escritas da história - um estudo da produção de Afranio Peixoto. In: GONDRA, J.; SILVA, J. História da Educação na América Latina: ensinar \& escrever. Rio de Janeiro: EdUERJ, 2011 a.

GONDRA, J.; SILVA, J. C. S. Textbooks in the history of education: notas para pensar as narrativas de Paul Monroe, Stephen Duggan e Afranio Peixoto. In: CONGRESSO BRASILEIRO DE HISTÓRIA DA EDUCAÇÃO, 6., 2011, Vitória. Anais, 2011 b.

GONDRA, J.; SILY, P. Narrativas da história e representações do Estado: um estudo do caso Stephen Duggan (1870-1950). In: INTERNATIONAL STANDING CONFERENCE FOR THE HISTORY OF EDUCATION (ISCHE), 33., 2011, San Luis de Potosi, Mexico. Anais...

LOPES, E. Júlio Afranio Peixoto. In: FAVERO, M. de L.; BRITTO, J. Dicionário de educadores no Brasil. Rio de Janeiro: EdUFRJ, 2002.

MENDONÇA, A. W. Anísio Teixeira e a universidade de educação. Rio de Janeiro: EDUERJ, 2002. 
MONROE, Paul. História da Educação. 11. ed. São Paulo: Cia. Editora Nacional, 1976. (Coleção Atualidades Pedagógicas. V. 34).

NUNES, C. Anisio Teixeira - a poesia da ação. Bragança Paulista: EDUSF, 2000.

PEIXOTO, A. Noções de História da Educação. São Paulo: Cia Editora Nacional, 1933.

PEIXOTO, A. Noções de História da Educação. 2. ed. São Paulo: Cia Editora Nacional, 1936 .

PEIXOTO, A. A educação da mulher. São Paulo: Cia Editora Nacional, 1936 b.

PEIXOTO, A. Noções de História da Educação. 3. ed. São Paulo: Cia Editora Nacional, 1942.

RIBEIRO, L. Afranio Peixoto. Rio de Janeiro: Edições Conde, 1950.

ROCHA, H. Recordação para professoras: a história da educação brasileira narrada por Afranio Peixoto. In: GONDRA, J. Dos arquivos à escrita da história - a educação brasileira entre o Império e a República. Bragança Paulista: EDUSF, 2002.

SANTOS, Theobaldo M. Noções de História da Educação. 9. ed. São Paulo: Cia Editora Nacional, 1960.

VIEIRA, Carlos. A escrita da História da Educação no Brasil: formando professores através de noções de história. In: Gondra, J.; Silva; J; História da Educação na América Latina: ensinar \& escrever. Rio de Janeiro: EdUERJ, 2011.

Recebido em 28 de março de 2011 e aprovado em 27 de maio de 2011.

Pro-Posições, Campinas, v. 22, n. 3 (66), p. 19-34, set./dez. 2011 


\section{Anexo I - Programa de História da Educação da Escola Normal do Rio de Janeiro - 1929}

HISTORIA DA EDUCAC̄̃O

1 - Importancia da Educação - Educar e instruir - Educaçấo phy ica, intellectual e moral - Conceito exacto da Educa-
çâo integral.

2 - Educação systematica - Fins e meios - Pedagogia empírica e pedagogia scientifica - Evolucão dos methodos - Importancla do estudo da Historia da Educação.

3 - Apreciaçío geral do problema da educação entre os po vos orlentaes - Influencia dos factores religlosos.

\section{$-85-$}

4 - A educação da Grecia - Esparta e Athenas - Os pedagogos - Importancia da obra de Socrates - Os grandes socra. ticos.

5 - O gymnasio, a mathematica, o ideal artistico - Estudo do Continente e Colonias.

6- A educaça em Roma - Periodo republicano e phase

7 - A educação entre os romanos, realizada sob o ideal politíco da democracia.

$8-0$ advento do Christianismo e sua influencia sobre a educą̧ão - 0 ideal christão no individuo, na familia e na socie. dade - Pedagogia patristica e pedagogia monastica.

9 - Acção educadora da Igreja no periodo medieval - Escolas abbeciaes e palatinas - Carlos Magno e a renascença carolingia.

10 - Pedagogia escolastica - As grandes uinversidades A vida intellectual nos ultimos seculos da Edade Média.

11 - Redacção humanistica - o Renascimento e a Reforma - Erasmo e Luthero.

12 - A reaccão catholica - A Companhia de Jesus e a pedagogia ignaciana - o Ratio Studiorum.

13 - Os Jansenístas e a obra pedagogica de Port Royal.

Pro-Posiçôes, Campinas, v. 22, n. 3 (66), p. 19-34, set./dez. 2011 
14 - Philosophos e pedagogos do seculo XVII - O Carte. sianismo - As iđéas pedagogicas de Locke - Comenius e o methodo intuitivo.

15 - Educadores francezes no seculo de Luis XIV - Bossuet e Fénelon.

16 - O philosophismo no seculo XVIII - Rousseau e o "Emilio" - Influencia das idéas de Rousseau sobre a educação.

17 - o philanthropismo - Basedow e suas idéas pedagogieas - A educação moral e a educağão physica.

18 - A instruccẽo primaria e as escolas populares na Europa durante o seculo XVIII - A revolução franceza e suas consequenclas na educação - As escolas normaes.

19 - A educacão dos anormaes no seculo XVIII - Cégos, surdos-mudos. Haùy e l'Epée.

20 - Pestalozzi e seus principios pedagogicos - Leonardo e Gertrudes - O Instituto de Yverdon - Critica da obra pestalozzlana.

21 - Pedagogos allemães no seculo XIX - Influencia do Idenllimo de Fichte - Richter e a "Levana".

Infanela.

99 - Froebel e seus systema educativo. Os Jardins da

28 - Merbart e seus discipulos - Exposição e critica das

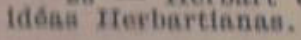

84 - Positiviamo e evolueionismo: influencia das novas theorfain na educacho - Spencer o seu tratado sobre a Educagáo - Hain a on pedasogos inglezes.

H6 - A eduença em Franga no seculo XIX - Dupantoup

\section{$-86-$}

- Vista geral sobre a educação na Europa durante o seculo XIX. o exemplo do Japấ e dos Estados Unidos.

26 - A psychologia applicada á Educação. - A Puericultura. - o methodo experimental - Psychometria - Wundt Binet - Claparéde.

27 - Montessori e seu Methodo de Pedagogia Scientifica Os precursores da obra montessoriana.

28 - A educação profissional, na Allemanha. 0 mestre escolar em 1870 e o mestre profissional em 1914 .

29 - O problema da educação $e$ as correntes actuaes. O aspecto social da educaç̃o - A escola nova e os seus tres principios fundamentaes - O principio da communidade, da escola unica e da escola do trabalho.

30 - A educação no Brasil, durante o periodo colonial Vinda da familia real e suas consequencias - Creacão dos eursos primarios - o ensino superior - Escola de Bellas Artes.

31 - A eđucação brasileira durante o segundo reinado.

32 - Periodo republicano - Estado actual da educacão no Brasil - A edueaça publica no Districto Federal - A nova organização escolar.

33 - Os grandes educadores brasileiros - Apreciação sum. maria de suas idéas - Valor de seu exemplo - Os "professores de energia".

Pro-Posições, Campinas, v. 22, n. 3 (66), p. 19-34, set./dez. 2011 